\title{
ANÁLISIS LEXICO-SEMÁNTICO DE LOS ANGLICISMOS VERBALES HOMÓNIMOS Y POLISÉMICOS $M^{a}$ Dolores Romero Lesmes \\ Instituto Universitario de Investigación José Ortega y Gasset
}

\section{ABSTRACT}

In this article, the linguistic phenomena of homonymy and polysemy are analyzed as understood by various linguists and lexicographers, such as Lyons (1977), Haensch et al (1982), Cabré (1993) or Vivanco (2003), among others. In addition, this text includes a lexical-semantic analysis of verbal Anglicisms in Spanish which are homonymous and polysemical. It distinguishes between necessary homonym verbs, such as chatear, and unnecessary homonym verbs, for example, aplicar. With regards to the polysemy verbs, there are verbs that inherit polysemy from English (surfear) and those verbs whose polysemy takes place once the borrowed word is established in Spanish (drenar).

KEYWORDS: Anglicisms, verbs, homonyms and polysemy

\section{RESUMEN}

En este artículo, se caracterizan los fenómenos lingüísticos de homonimia y polisemia según han sido entendidos por diferentes lingüistas y lexicógrafos, como Lyons (1977), Haensch et al. (1982), Cabré (1993) o Vivanco (2003), entre otros. Posteriormente, se realiza un análisis léxicosemántico de los anglicismos verbales homónimos y polisémicos. Por un lado, se distinguen los verbos homónimos necesarios, como chatear y, por otro, los verbos homónimos innecesarios, por ejemplo aplicar. En los verbos polisémicos, están los verbos que heredan la polisemia del inglés (surfear) y los verbos cuya polisemia se produce una vez que el préstamo se asienta en español (drenar).

PALABRAS CLAVE: anglicismos, verbales, homónimos y polisémicos 


\section{CARACTERIZACIÓN DE HOMONIMIA Y POLISEMIA}

Los conceptos de homonimia y de polisemia hacen referencia a la relación entre la forma del signo lingüístico y su significado. Más concretamente, ambas nociones suponen la existencia de más de un significado asociado a una misma forma. Dado que no existe una clara línea divisoria entre homonimia y polisemia, como apunta Lewandowski (1995), es frecuente que los diccionarios consideren determinados lemas como polisémicos, a pesar de ser homónimos, y viceversa, lo que afecta tanto a la macroestructura del diccionario como a su microestructura en la ordenación de acepciones.

Los criterios principales que los lexicólogos y lexicógrafos han tenido en cuenta para distinguir entre homonimia y polisemia están basados en la etimología y en la conciencia lingǘstica de los propios hablantes. El criterio etimológico se basa en el origen de la palabra y en su evolución histórica. Así, la polisemia solo se da en aquellos casos en los que una sola forma desarrolla diferentes significados. Por ejemplo, una palabra como banco, con un único origen (del francés bank), tiene al menos tres significados: 1) "asiento de madera", 2) "conjunto de peces" y 3) "establecimiento público de crédito". La homonimia, por su parte, supone la existencia de una forma procedente de distintos étimos y, consecuentemente, con distintos significados según el étimo. Así ocurre, por ejemplo, en la palabra polo que presenta dos orígenes distintos: uno del latín polus, al que se le asocian dos significados ("punto en el que el eje corta una superficie de revolución" y "helado"), y otro del inglés polo que a su vez tiene dos significados ("juego practicado entre jinetes", "camiseta").

De esta manera, según el criterio etimológico, banco es una palabra polisémica, dado que los tres significados de banco se han desarrollado a partir de una única forma; en cambio, polo es una palabra homónima porque sus significados están asociados a formas con distinto origen (latín, inglés), pero que han coincidido formalmente en la evolución de la lengua. Generalmente, la homonimia ocurre cuando una lengua adopta préstamos de otra, de modo que, en algunos casos, los préstamos pueden confluir con unidades léxicas existentes en la lengua. Dado que son palabras distintas, es lógico que tengan significados que no están relacionados, a diferencia de lo que suele ocurrir en la polisemia.

Sin embargo, el criterio etimológico no siempre resulta decisivo para diferenciar entre homonimia y polisemia, ya que en muchas lenguas la procedencia de algunas voces no es totalmente clara. Así, Lyons (1977) apunta que existen muchas palabras inglesas cuya derivación histórica no es del todo precisa, puesto que algunas voces que proceden del inglés antiguo se han confundido en el inglés medio, como es el caso de ear1 (esp. 'oreja') y ear2 (esp. 'espiga'). No obstante, Haensch et al. (1982) señala que el criterio etimológico no se debe rechazar totalmente cuando analizamos los vocablos homónimos y 
polisémicos, dado que este criterio resulta verdaderamente útil para la realización de diccionarios etimológicos, los cuales parten del origen de la palabra para llegar a su uso actual, de modo que la disposición de las acepciones sigue un criterio etimológico. ${ }^{1}$

El segundo criterio que se utiliza para distinguir entre homonimia y polisemia es la conciencia lingüística de los hablantes. Según esta idea, la polisemia existe cuando el hablante encuentra afinidad semántica entre los contenidos diferentes que puede presentar una sola palabra. En el caso de la homonimia, el hablante no establece ninguna afinidad semántica entre los significados de una palabra. Pongamos algún ejemplo que ilustre esta diferencia. Una palabra como caballo es polisémica al contar con tres acepciones: 1) "animal", 2) "aparato de gimnasia" y 3) "pieza de juego en ajedrez". El hablante es capaz de establecer una relación entre los tres significados de caballo, dado que existe una similitud entre la entidad denominada por caballo en cuanto animal y las entidades a las que también hace referencia esta palabra. Por el contrario, una palabra como macho, que cuenta con dos sentidos: ("animal de género masculino" y "mazo grande que hay en las herrerías"), es homónima, puesto que el hablante no puede establecer una afinidad semántica entre los dos significados asociados a este significante.

Aunque el criterio de la conciencia lingüística de los hablantes constituye una apreciación útil para distinguir estos dos fenómenos lingüísticos, no puede ser considerado determinante para diferenciar la homonimia y la polisemia, dado que no siempre es posible encontrar relaciones. Así, volviendo a los ejemplos anteriores, puede ocurrir que un hablante no encuentre ninguna afinidad entre los significados de caballo o que, por el contrario, encuentre una afinidad metafórica entre macho animal de género masculino y macho en cuanto mazo grande.

Una vez analizadas las diferencias entre homonimia y polisemia, es el momento de ocuparnos del modo en que se originan estos fenómenos lingüísticos. La polisemia está basada en la variación semántica de un mismo vocablo, por lo que las distintas acepciones están relacionadas semánticamente. Las voces más comunes suelen ser las más polisémicas, como por ejemplo sucede con la palabra cosa, procedente del latín causa, que cuenta en el DRAE con numerosas acepciones, de las que destacamos tres significados: 1) "todo lo que tiene entidad, ya sea corporal o espiritual, natural o artificial, real o abstracta", 2) "objeto inanimado, por oposición a ser viviente" y 3) "asunto, tema o negocio". Las definiciones de cosa están relacionadas debido a la ampliación semántica de la acepción primera. La ampliación de significado de

\footnotetext{
1 Frente al criterio etimológico, determinados diccionarios adoptan un criterio de uso para ordenar las acepciones de las palabras polisémicas, por ejemplo el DSLE o el DUEA.
} 
una palabra es uno de los recursos más productivos a la hora de aumentar el léxico en una lengua, como apunta Cabré (1993). Dado que el origen de las palabras que son polisémicas se basa en el parecido entre dos nociones, es posible crear un nuevo significado a partir de otro próximo. Así, retomando el ejemplo anterior, el contenido básico de cosa se encuentra en la primera acepción, mientras que los significados de las acepciones dos y tres son el resultado de la ampliación semántica por especificación del significado más general de la acepción primera.

Por su parte, en la creación de homónimos intervienen numerosos factores de índole morfológica y semántica. Así, nudo presenta dos significados pertenecientes a dos formas distintas: una derivada del acortamiento de desnudo y otra procedente del latín nodus (Vivanco 2003). Otros homónimos se producen a partir de la alternancia de vocales, como es el caso de la palabra orca como "animal acuático" y la forma urca con el significado de "tipo de embarcación de transporte". Otro factor para la creación de homónimos es la adición de prefijos, como en el ejemplo citado en Vivanco (op. cit.): la palabra reo presenta la forma prefijada correo con el significado de "número de acusados culpables de un mismo cargo", la cual coincide con la palabra con el significado "servicio público de envío por correspondencia". La adjunción del morfema femenino también puede dar lugar a la formación de homónimos: así, mica se refiere tanto al mineral como a la hembra del mico. La última posibilidad que citaremos es la unión de los sufijos españoles -ar y -ear a bases verbales inglesas, como ocurre con la mayoría de los verbos homónimos que estudiamos (chat $>$ chatear, test $>$ testar). Estos verbos adaptados coinciden formalmente con verbos ya existentes en la lengua española: chatear "tomar chatos de vino"; testar "hacer testamento", de modo que surgen en la lengua homónimos.

La acuñación de homónimos por calco semántico (capítulo I apartado 2.2.3) es el recurso más productivo en el léxico terminológico y es frecuente en las traducciones que se realizan del inglés, dado que el léxico científico y tecnológico se transmite mayoritariamente a través de esta lengua. Es posible distinguir dos clases de calcos semánticos: los innecesarios y los necesarios. Los calcos semánticos innecesarios se producen al traducir falsos amigos $\mathrm{O}$ cognados falsos, los cuales conviven con vocablos españoles, por lo que inducen a la confusión semántica del término, como, por ejemplo introducir (ing. introduce) por presentar o actualidad (ing. actualy) por realidad. Los calcos semánticos necesarios resultan cuando se hacen traducciones de conceptos inexistentes en español y se crea un vocablo que coincide morfológicamente con otro vocablo que ya existe en la lengua. Así, el adjetivo agresivo con el significado originario en español de "violento" ha ampliado su contenido semántico por influencia del valor significativo inglés "emprendedor, dinámico, activo” (Gómez Capuz 2004). De esta manera, se asienta un significado nuevo 
asociado a un significante de la lengua que no mantiene relación alguna con el significado primero. Por tanto, los homónimos por calco semántico suponen a su vez un calco morfológico, dado que se adapta una voz inglesa a una palabra existente en la lengua española. Vivanco (2003) denomina 'homonizantes' a este tipo de calcos semánticos necesarios.

Desde otra perspectiva, Lyons (1977) distingue dos tipos generales de homonimia: la absoluta y la parcial. Para que ocurra la homonimia absoluta, deben cumplirse tres requisitos: desconexión semántica, igualdad gráfica y equivalencia gramatical de las formas. Esto sucede, por ejemplo, con la voz polo que explicamos anteriormente. Así, polo es un homónimo absoluto ya que los significados de polo1 y polo2 no mantienen relación semántica; gráficamente son iguales; los dos significados de la voz polo pertenecen a la misma categoría gramatical (son sustantivos) y sus orígenes son distintos: polo1 proviene del latín y polo2, del inglés.

La homonimia parcial gramatical, según la denomina Lyons (1977), se refiere a vocablos que, coincidiendo gráficamente, tienen desconexión semántica y no son iguales en la forma gramatical; por ejemplo, la forma anular es tanto verbo como adjetivo. Otros tipos de homonimia parcial son la homógrafa y la homófona, que consisten en la falta de simetría entre la grafía y el sonido. Así, la homonimia parcial homógrafa se da en español en casos como las palabras que pueden escribirse con tilde o sin ella: cómo (pronombre interrogativo) y como (primera persona del verbo comer). La homonimia parcial homófona, por su parte, tiene su origen en la entonación de ciertas palabras, como por ejemplo en alá interjección y en Alá dios de los musulmanes. ${ }^{2}$

En resumen, aunque el criterio etimológico y la conciencia de los hablantes no son factores decisivos para determinar la homonimia y la polisemia, pueden servir como criterios a la hora de definir ambos conceptos. Así, las palabras polisémicas contienen varios significados relacionados semánticamente por proceder de un único origen y exhibir la misma forma; las palabras homónimas, en cambio, coinciden en la forma pero sus significados no tienen conexión semántica, dado que presentan orígenes distintos. Los calcos semánticos 'homonizantes' aportan a nuestra lengua significados nuevos y coinciden formalmente con vocablos que ya existen en español, de modo que nos encontramos con una misma forma con origen distinto, a la que se asocian significados diversos.

\footnotetext{
2 La homofonía se refiere a vocablos que se escriben de forma distinta, pero se pronuncian igual, como vaca/baca, hola/ola. La homografía, en cambio, se refiere a los vocablos que se escriben igual, pero la pronunciación es distinta. Dada la relación tan estrecha entre grafía y sonido en español, no existen homógrafos en esta lengua. En inglés, pueden darse varios fenómenos de homografía, como la palabra lead que tiene dos realizaciones fónicas a las que corresponden dos significados: [li:d] (esp. 'dirigir'); [LEd] (esp. 'plomo').
} 
La diferencia entre homonimia y polisemia resulta relevante en nuestro estudio, puesto que existen varios anglicismos verbales que son polisémicos, esto es, verbos que, una vez adaptados al español, desarrollan diferentes significados o bien toman prestadas del inglés varias acepciones. Otros anglicismos verbales, por el contrario, son homónimos, dado que la forma que se toma del inglés coincide formalmente con un verbo que ya existe en español. A continuación, pasamos a analizar los anglicismos verbales homónimos y polisémicos.

\section{VERBOS HOMÓNIMOS}

Varios verbos que proceden del inglés son homónimos, pues la forma adaptada del préstamo inglés ha confluido con un verbo existente en español, como en los verbos alocar, aplicar, cachar, chatear, empoderar, flamear, jaquear, pastear, testar/testear, tunear, zapear. Según hemos visto en el apartado anterior, los verbos citados son homónimos porque gráficamente son iguales y pertenecen a la misma categoría gramatical. Asimismo, el significado general y el especializado presentan una desconexión semántica al proceder de orígenes distintos.

Para analizar dichos anglicismos verbales, es preciso diferenciar entre el significado general, esto es, el significado que tiene cada uno de ellos en la lengua común, según queda recogido en el DRAE, por ejemplo, y el significado especializado, es decir, el significado que adquiere el verbo dentro de las lenguas de especialidad y que suele tomarse como préstamo del inglés. Dado que los diccionarios de lengua general suelen incluir también léxico de especialidad, las palabras homónimas quedan recogidas en entradas distintas, si el diccionario asume la homonimia como criterio en la disposición de los lemas, o como acepciones distintas de una misma entrada en los diccionarios que adoptan planteamientos exclusivamente polisémicos en la macroestructura. Así, el DRAE diferencia entre homonimia y polisemia, de modo que las palabras homónimas están recogidas en entradas distintas. Por ejemplo, el verbo testar aparece en el DRAE con tres entradas: testar1 "hacer testamento", testar2 "atestar" y testar3 "someter algo a un control o prueba". Por el contrario, un diccionario como el DUEA sigue un criterio polisémico en la ordenación de los lemas, por lo que codifica las palabras homónimas en una misma entrada. De este modo, testar aparece con dos acepciones distintas: 1) "hacer testamento" y 2) "controlar o comprobar mediante un test".

Veamos con detalle cada uno de los verbos. Comencemos por el verbo alocar, el cual está definido en el DRAE con el significado de "causar locura", dada su estructura morfológica como verbo deadjetival procedente de loco. Con esta forma verbal ha confluido el verbo procedente del inglés to allocate con el significado especializado "asignar o distribuir algo". Etimológicamente, el 
verbo inglés viene del latín medio allocatus, participio pasado de allocare. Como podrá advertirse, los dos significados del verbo alocar no se relacionan semánticamente, aunque sean iguales formalmente, debido a la supresión en la forma procedente del inglés de la doble consonante $l$ y a la sustitución de la terminación -ate por el sufijo verbal -ar (allocate $>$ alocar). Así pues, la forma especializada alocar es un verbo homónimo, producido por un calco semántico homonizante, que aporta un significado nuevo al español en el campo de la informática. Por ello, el verbo alocar es un homónimo absoluto, en cuanto que las dos formas presentan desconexión semántica, son idénticas gráficamente y comparten la misma categoría gramatical.

En el caso de aplicar, procedente del latín applicare, presenta el significado no especializado de "poner algo sobre otra cosa o en contacto de otra cosa" (DRAE). El significado especializado "solicitar algo por escrito" proviene del verbo inglés to apply que, al igual que el significado general, tiene su origen en el latín applicare. La adaptación formal del verbo aplicar se ha llevado a cabo a partir de la reducción de la doble consonante $p$ y de la sustitución de la terminación -ate por el sufijo español -ar. Si se tiene en cuenta el principio de economía de las lenguas, la acuñación de este homónimo es innecesaria, al existir en español el vocablo solicitar para referirse a la acción de "pedir algo por escrito".

El verbo cachar, que procede del sustantivo cacho, está definido en los diccionarios generales como "hacer cachos o pedazos algo". El significado especializado deriva del verbo inglés to cacht, con al menos cinco acepciones en inglés, de las cuales el español ha tomado el significado relacionado con el campo del deporte: "en algunos juegos, agarrar al vuelo la pelota que un jugador lanza a otro" (DRAE). Al igual que aplicar, el verbo cachar es un calco del inglés innecesario, porque la lengua española tiene los verbos coger y agarrar para designar la misma acción. El uso del término especializado cachar se da solamente en América Latina y no es muy común en el español peninsular.

Otro ejemplo de homónimo es el verbo chatear, procedente del euskera chato "vaso de vino", el cual está definido en el DRAE como "beber chatos de vino". Con este verbo ha confluido el verbo procedente del inglés to chat, originalmente del inglés medio chatten, forma corta de chatteren. El verbo inglés tiene al menos tres significados, uno de los cuales pertenece al área de especialidad de la informática y ha pasado al verbo español con el significado de "mantener una conversación mediante el intercambio de mensajes electrónicos" (DPD). Morfológicamente, el verbo chatear es el resultado de la unión de la base inglesa chat y el sufijo -ear. La formación semántica del verbo chatear ha tenido lugar por un calco semántico homonizante, que coincide con el significado general de chatear. Por tanto, el verbo chatear es un homónimo absoluto. 
Otro caso de verbo homónimo es empoderar, del verbo latino potère, formado según potes, definido en el DRAE como "dicho de una persona: dar poder a otra para que la represente en juicio o fuera de él". Con la forma verbal española ha confluido la adaptación del verbo inglés to empower con dos acepciones, el español ha tomado el significado especializado "conceder poder a un colectivo desfavorecido socio-económicamente para que, mediante su autogestión, mejore sus condiciones de vida" (DPD). El verbo empoderar, como préstamo del inglés, es el resultado de la adaptación fonológica de la forma inglesa a la grafía española: cambio del fonema labial $/ w /$ por el dental / $d /$ y la adjunción del sufijo -ar a la base inglesa. Semánticamente, empoderar es un calco homonizante, ya que el nuevo significado da lugar a un significado distinto del verbo español original. Como algunos verbos anteriores, el verbo empoderar es un homónimo absoluto.

El verbo flamear, que proviene del latín flammare, está definido en el DRAE como "rociar un alimento con un licor y prenderle fuego". El significado especializado tiene su origen en el verbo inglés to flame, procedente del latín flamma. El verbo inglés transitivo tiene tres acepciones, de las cuales el español ha tomado la que está relacionada con la informática: "opinar o criticar algo a alguien, expresándolo de forma franca o apasionada en un mensaje de correo electrónico". ${ }^{3} \mathrm{El}$ anglicismo verbal es el resultado de la cancelación de la vocal - $e$ en la base inglesa flame y la adjunción del sufijo español -ear: flam $(e)+$ ear $>$ flamear. Dado que este término da lugar a un nuevo significado que expresa una acción diferente del significado general, es considerado un homónimo absoluto, producido por un calco homonizante.

En el caso del verbo jaquear, cabe señalar que es un préstamo del árabe y tiene en español el significado "dar jaques" (DRAE). El significado especializado proviene del verbo inglés to hack que tiene al menos cuatro acepciones, una de las cuales ha pasado al español como préstamo dentro del campo de la informática: "robar algo". El verbo jaquear, como préstamo del inglés, es el resultado de la adaptación fonológica de la forma inglesa a la grafía española: cambio de la glotal $/ h /$ por la velar $/ x /$, con la grafía $j$, y cambio de la grafía ck por qu para la representación del fonema velar $/ k /$. A esta base se adjunta el sufijo verbal -ear. Semánticamente, jaquear es el producto de un calco homonizante, ya que el nuevo significado da lugar a un contenido distinto del verbo español original. Como algunos verbos anteriores, el verbo jaquear es un homónimo absoluto.

Otro ejemplo de homonimia es el verbo pastear, cuyo significado general es "llevar el ganado a pastar", procedente del latín pasto. En su calidad de término especializado, presenta el significado "pegar, copiar textos"

\footnotetext{
${ }^{3}$ La definición de flamear es una adaptación de la que aparece en el GTI.
} 
(DRAE) que proviene del verbo inglés to paste y este, a su vez, del inglés medio anglo-francés y del latín antiguo pasto. Cabe destacar que tanto la forma española como la inglesa tienen el mismo origen latino; sin embargo, en cada lengua se ha producido una especialización. Así, el verbo pastear en español está tomado directamente del latín, por eso mantiene el significado originario de pasto; el verbo pastear tomado del inglés, en cambio, presenta un significado distinto, aunque sea una palabra que procede también del latín. El verbo inglés tiene al menos cinco valores significativos, de los cuales el español solo ha tomado prestado el significado especializado que está relacionado con la informática. Morfológicamente, pastear es el resultado de la pérdida de la vocal $-e$ de la base inglesa paste y la adjunción del sufijo - ear: past $(e)+-$ ear $>$ pastear. Al igual que sucede con los verbos aplicar y cachar, el verbo pastear es un calco semántico innecesario, puesto que en español existen los verbos pegar o copiar para definir la acción de "unir textos en un ordenador".

Otro verbo homónimo es testar con los significados generales "hacer testamento", del latín testari "testamento", y "testificar"; por tanto, es un verbo polisémico ya en español. El significado especializado "someter algo a un control o prueba" está tomado del verbo inglés to test, que proviene del francés tester y este, a su vez, del latín testari. Aunque los dos significados tienen su origen en la misma lengua vernácula, han desarrollado contenidos diferentes, por ello el verbo testar es un homónimo absoluto. Desde el punto de vista morfológico, el verbo testar se forma a partir de la base inglesa test y del sufijo ar.

En cuanto al verbo tunear, el significado general es "hacer vida de tuno", del argot francés tune. Con la forma verbal española ha confluido la adaptación del verbo inglés to tune con cuatro acepciones, una de las cuales exhibe el significado especializado "personificar un coche", que ha pasado como préstamo al español. Morfológicamente, tunear es el resultado de la cancelación de la vocal - e en la base inglesa tune y la adjunción del sufijo español -ear: tun $(e)+$-ear >tunear. Al igual que algunos verbos anteriores, este verbo lo hemos considerado un verbo homónimo originado por un proceso de calco homonizante, dado que añade un significado nuevo a un verbo ya existente en español. Además, tunear es un homónimo absoluto porque el significado general y el especializado no tienen relación semántica, presentan una forma gráfica semejante y ambos pertenecen a la categoría verbal.

Por último, el verbo zapear está definido en el DRAE como "espantar al gato con la voz zape", proveniente de la onomatopeya zape. La forma especializada es un préstamo del verbo inglés to zap "cambiar reiteradamente de canal de televisión por medio del mando a distancia” (DPD). Morfológicamente, zapear está formado por la adjunción del sufijo -ear a la base inglesa zap. Como la mayoría de los verbos anteriores, la forma procedente del inglés es un calco semántico homonizante, que da un significado nuevo al 
verbo existente en la lengua general. El verbo zapear es un homónimo absoluto, dado que sus significados no se corresponden semánticamente, gráficamente son iguales, ambos pertenecen a la categoría verbal y presentan orígenes distintos.

Como hemos visto, la existencia de algunos verbos homónimos en el español actual se debe a la adaptación morfológica de préstamos del inglés. Es importante resaltar que la mayoría de estos verbos pertenece al campo de la informática, como alocar, aplicar, chatear, flamear, jaquear o pastear. Los verbos empoderar, testar, tunear y zapear son los únicos verbos homónimos de nuestro corpus que no están vinculados a esta área, aunque se refieren a términos relativamente nuevos relacionados con los avances tecnológicos y sociales. Los verbos aplicar, cachar y pastear han sido considerados homónimos innecesarios, ya que existen los verbos españoles solicitar, agarrar y copiar, respectivamente, para referirse a las mismas acciones. Por último, algunos de estos verbos homónimos como chatear, empoderar, testar o zapear gozan de mayor vitalidad como términos especializados que como palabras de la lengua general, ya en desuso.

\section{VERBOS POLISÉMICOS}

Como dijimos en el apartado 1, son polisémicos aquellos términos que tienen al menos dos significados diferentes aunque relacionados semánticamente. Entre los anglicismos verbales son polisémicos chequear, chutar, craquear/crackear, drenar, flipar, esclerotizar, indexar, procesar y surfear. Los verbos mencionados dan lugar a dos grupos según el origen de la polisemia. En uno, los verbos heredan la polisemia del inglés, es decir, el verbo español toma prestada más de una acepción (chequear, chutar, craquear/crakear, esclerotizar, procesar, surfear); en otro, la polisemia se ha producido en español como extensión significativa una vez adaptado el anglicismo verbal (drenar, flipar, indexar). Pasemos a analizar, en primer lugar, los verbos con polisemia heredada del inglés.

El verbo chequear proviene del verbo inglés to check, que tiene al menos diez acepciones en esta lengua. El español ha tomado dos sentidos: "examinar, comprobar algo" y "hacerse un chequeo" (DRAE), contenido que en inglés se expresa con la forma to check up. El primer significado es la base de la creación del segundo, por ello este último es más específico y está relacionado con el campo de la medicina. Desde el punto de vista morfológico, chequear se ha formado por la adjunción del sufijo -ear a la base inglesa check, una vez adaptada la forma.

Otro verbo polisémico es el verbo chutar, procedente del verbo inglés to shoot, con al menos siete acepciones en esta lengua. El español ha tomado 
prestado dos significados: la acepción relacionada con el deporte "lanzar fuertemente el balón con el pie" y la relacionada con la droga "inyectarse droga" (DRAE), de uso pronominal en español. El primer significado es la base del concepto del verbo chutar; el segundo es la ampliación semántica producida ya en inglés y restringida a un determinado registro. El verbo chutar es el resultado de la adaptación fonológica $/ \mathrm{S} />/ \mathrm{t} /$, representado gráficamente como $c h$, y gráfico oo $>u$, más la adjunción del sufijo - ar a la base adaptada.

El verbo craquear o crackear hereda los dos significados que presenta el verbo inglés to crack, con numerosas acepciones en esta lengua. El español ha tomado el significado relacionado con la física "romper por elevación de temperatura las moléculas de ciertos hidrocarburos con el fin de aumentar la proporción de los más útiles" (DRAE) y el referido a la informática "introducir algo en un sistema ajeno". Morfológicamente, la forma crackear conserva la base del verbo inglés a la que se une el sufijo -ear. La forma craquear se ha adaptado a la pronunciación española: cambio de las grafías $k$ por qu y adjunción del sufijo -ear.

En cuanto al verbo esclerotizar, del inglés to sclerotize, toma prestada las dos acepciones del inglés, el significado relacionado con la medicina "endurecer un tejido u órgano por la formación de escleroproteínas" y la acepción "detener algo en su proceso de progresión" (DRAE). El primer significado es la base del concepto del verbo esclerotizar a partir del cual se ha originado metafóricamente la segunda acepción relacionada al proceso de estancamiento que se produce en algo. Formalmente, el verbo esclerotizar se forma con la adjunción de la vocal edelante de la consonante $s$ - en la base inglesa y la sustitución del sufijo inglés ize por el sufijo español -izar.

En el caso del verbo procesar, del verbo inglés to process, cabe señalar que el verbo español ha asumido las acepciones relacionadas con el derecho "tratar a alguien como presunto reo de delito" y con el campo de la informática "someter datos o materiales a una serie de operaciones programadas" (DRAE). Morfológicamente, el verbo procesar se ha formado mediante la adición del sufijo - ar a la base inglesa process, con reducción del grupo consonántico final.

El verbo surfear, préstamo del verbo inglés to surf, ha tomado prestadas dos acepciones: "practicar surf" (DPD) y, en el área de la informática, "explorar para buscar información". La primera acepción es la originaria, a partir de la cual se ha originado metafóricamente el segundo significado al comparar la práctica del deporte del surf con la acción de navegar por Internet. Desde el punto de vista morfológico, el verbo surfear es el resultado de la unión del sufijo - ear a la base inglesa surf.

Una vez analizada la polisemia heredada del inglés, pasemos a estudiar los verbos con polisemia producida en español como extensión significativa del anglicismo verbal. 
El verbo drenar, también polisémico, proviene del inglés to drain, que presenta tres acepciones en esta lengua. Al español han pasado el contenido relacionado con la agricultura "dar salida y corriente a las aguas muertas o a la excesiva humedad de los terrenos, por medio de zanjas o cañerías" y el significado relacionado con la medicina "asegurar la salida de líquidos, generalmente anormales, de una herida, absceso o cavidad" (DRAE), a partir del primer contenido se ha desarrollado en español el significado "quitar, retirar dinero para sanear" en el área de economía. Como podemos apreciar, los significados de drenar se relacionan semánticamente, al establecer una semejanza entre el agua, los líquidos y el dinero. Formalmente, el verbo drenar ha sufrido una adaptación gráfica en español mediante el cambio $a i>e$ y la adjunción del sufijo - ar a la base adaptada.

Otro ejemplo de verbo polisémico es flipar que procede del verbo inglés to flip, con numerosas acepciones en esta lengua. El español ha tomado prestado del inglés el significado "enloquecer o perder la cabeza" y después ha ampliado su contenido semántico con los significados: 1) "estar bajo los efectos de una droga"; 2) "estar o quedar entusiasmado" y 3) "agradar o gustar mucho" todos en el DRAE. Morfológicamente, el verbo flipar se ha formado por la adjunción del sufijo - ar a la base inglesa del verbo inglés to flip.

Por último, el verbo indexar, procedente del verbo inglés to index, presenta tres acepciones en esta lengua. El español ha tomado como préstamo el significado "hacer índices", sobre el que se ha desarrollado una segunda acepción relacionada con la economía "registrar ordenadamente datos e informaciones, para elaborar su índice" (DRAE). Desde el punto de vista morfológico, el verbo indexar se forma a partir de la base del verbo inglés al que se añade el sufijo -ar.

Según lo visto, los anglicismos verbales polisémicos son el resultado de un proceso morfosemántico. Morfológicamente, se toman las bases de los verbos ingleses del que proceden y se unen a ellas sufijos verbales españoles. Semánticamente, se adoptan del inglés uno o varios significados y después los verbos prestados, una vez asentados en la lengua, pueden ampliar sus contenidos. Varios verbos que hemos considerado polisémicos en nuestro estudio léxico (drenar, craquear/crackear, procesar y surfear) presentan acepciones en campos de especialidad diferentes.

\section{BIBLIOGRAFÍA}

AguAdo DE CEA, Guadalupe (1994): Diccionario comentado de terminología informática: unificación racional de términos, anglicismos y galicismos, pautas de traducción, semántica informática, glosario inglés-español. Madrid, Paraninfo. [DCTI] 
AlfonseCA, Manuel: Diccionario Unificado de Términos Informáticos: Versión electrónica: $\quad$ http://www.ii.uam.es/esp/alumnos/terminologiainformativa.html. [DUTT]

FERNÁNDEZ CALVO, Rafael: Glosario de términos informáticos. Versión electrónica: http://www.atheneum.doyma.es Editada por ATI. [GTI]

Cabré Castellví, Ma Teresa (1993): La terminología. Teoría, metodología, aplicaciones. Barcelona, Antártica / Empúries.

Gómez CAPuz, Juan (2004): Préstamos en español: Lengua y sociedad. Madrid, Arco Libros.

Gutiérrez CuAdrado, Juan. (dir.) (1996): Diccionario Salamanca de la lengua española. Salamanca, Santillana. [DSLE]

HaEnsCH, W. et al. (1982): La lexicografía. De la lingüistica teórica a la lexicografía práctica. Madrid, Gredos.

LEWANDOWskI, Theodor. (1995): Diccionario de Lingüistica. Madrid, Ediciones Cátedra.

LyONS, John (1977): Semantics. Cambridge, Cambridge University Press. Versión española en R. Cerdá (1980). Barcelona, Teide.

Maldonado GonzÁLEz, Concepción (dir.) (1996): Diccionario de uso del español actual. Madrid, SM. [DUEA]

Real ACADEmia EsPañola (2001): Diccionario de la Lengua Española. Madrid, Espasa Calpe. [DRAE]

- (2005): Diccionario panhispánico de dudas. Madrid, Santillana. [DPD]

Romero Lesmes, María Dolores (2010): Estudio Léxico-Semántico de los Anglicismos Verbales en el Español Normativo. Tesis doctoral sin publicar. Madrid, Universidad Complutense de Madrid.

Vivanco Cervero, Verónica (2003): Homonimia y polisemia: teoría semántica y aplicación lexicográfica. Buenos Aires, Ediciones del Sur. 